\title{
Recurrent atrial flutter, a rare cause of cardiomyopathy in early infancy
}

\author{
*Sham Balkisanji Lohiya ${ }^{1}$, Sachin Damke², Richa Chaudhary ${ }^{1}$ \\ Sri Lanka Journal of Child Health, 2021; 50(4): 728-730 \\ DOI: http://doi.org/10.4038/sljch.v50i4.9900 \\ (Keywords: Atrial flutter, Cardiomyopathy, Congestive cardiac failure, Recurrent)
}

\section{Introduction}

Atrial flutter is very uncommon in the neonate and in early infancy ${ }^{1}$. About $1-3 \%$ of neonates may have cardiac rhythm abnormalities ${ }^{2}$. Majority of supraventricular tachycardia (SVT) occurring in neonates without structural heart defects are atrioventricular re-entry tachycardia (AVRT) caused by an accessory pathway (AP) and atrial flutter (AF) which is rarely seen after the neonatal period $^{2}$. Atrial flutter is an uncommon type of fetal and neonatal arrhythmia based on the mechanism of re-entry ${ }^{1}$. Out of all neonatal cardiac arrhythmias $32 \%$ are $\mathrm{AF}^{3}$. Mostly, it is well tolerated and asymptomatic, but sometimes it can lead to cardiac failure ${ }^{4,5}$. Majority of cases respond to cardioversion and never revert to flutter but resistant cases can occur ${ }^{4,5}$. Here we present a young infant with symptomatic resistant recurrent atrial flutter managed successfully with multipronged therapy.

\section{Case report}

A 40-day-old male infant was taken to a private hospital with complaints of cough and cold since 3 days, followed by respiratory distress. He was admitted to the paediatric intensive care unit (PICU) of that hospital and on electrocardiogram (ECG) monitor was diagnosed to have atrial flutter. Later an echocardiogram was done which revealed cardiomyopathy. He was treated accordingly with adenosine, furosemide, digoxin and propranolol and received cardioversion too as per documentation. He was then referred to our hospital, which is a tertiary care institute, in view of recurrent atrial flutter and non-improving cardiac functions. According to the mother, there

${ }^{1}$ Associate Professor, ${ }^{2}$ Professor and Head of Department, Department of Paediatrics, Jawaharlal Nehru Medical College, Sawangi, Wardha, Maharashtra, India

*Correspondence: shamlohiya85@gmail.com

iD https://orcid.org/0000-0003-0839-1168

(Received on 04 November 2020: Accepted after revision on 18 December 2020)

The authors declare that there are no conflicts of interest

Personal funding was used for the project.

Open Access Article published under the Creative Commons Attribution CC-BY (c) (i) License had been similar complaints at 1 month of age but they were relieved with 2 days of some oral medications. At that time he was not diagnosed to have SVT. The birth weight was $2.7 \mathrm{~kg}$. Birth history was uneventful.

On admission to our centre, baby had nasal flaring, tachypnoea and the heart rate was fluctuating from 190 to $210 / \mathrm{min}$. He had gallop rhythm with bilateral fine crepitations. Liver was palpable $3 \mathrm{~cm}$ below the costal margin. On the ECG he had multiple $\mathrm{P}$ waves with saw tooth appearance, suggestive of atrial flutter. Atrial rate was 400-450 /minute and ventricular rate was 70-80 / minute (Figure 1).

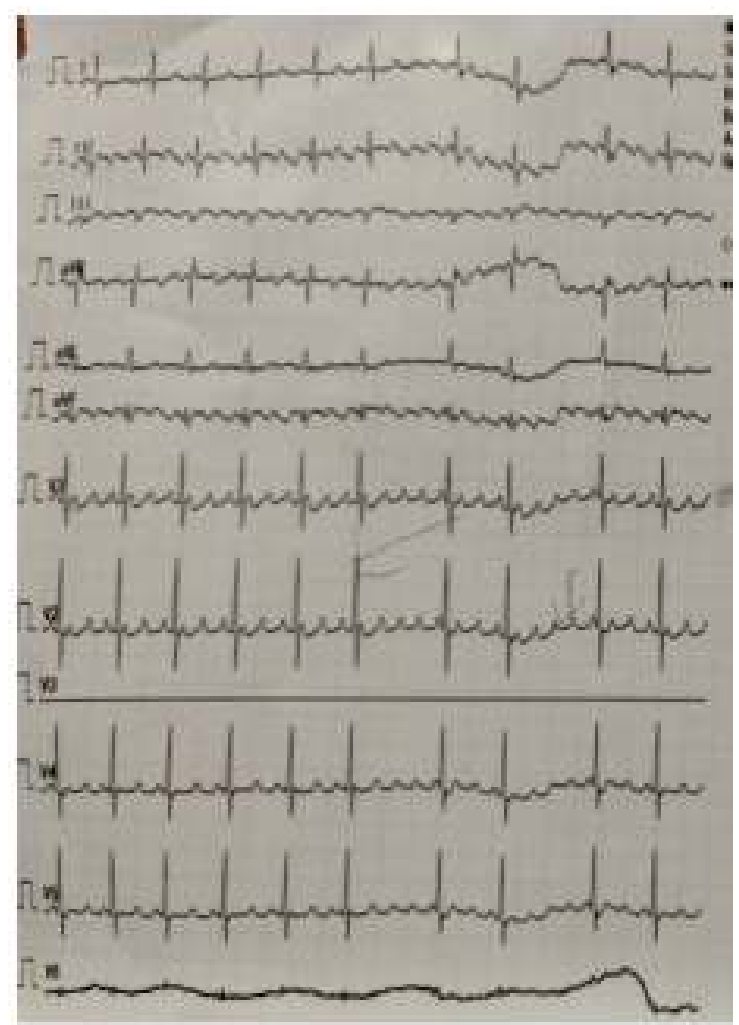

Figure 1: ECG on admission showing multiple $P$-waves (f wave) with saw tooth appearance with atrioventricular conduction rate $2: 1$ to $4: 1$

He was started on an infusion of milrinone 0.25 $\mu \mathrm{g} / \mathrm{kg} / \mathrm{min}$ for suspected cardiac failure and injection amiodarone $5 \mu \mathrm{g} / \mathrm{kg} / \mathrm{min}$ in view of resistant atrial flutter and because the infant was already on digoxin and propranolol. Propranolol was withheld considering the acute heart failure. 
The complete blood count, liver function tests and kidney function tests were normal. The thyroid profile (T4- $7.46 \mu \mathrm{g} / \mathrm{dl} \mathrm{TSH}-0.87 \mu \mathrm{IU} / \mathrm{ml}$ ), calcium $(8.9 \mathrm{mg} / \mathrm{dl})$, magnesium $(2.1 \mathrm{mg} / \mathrm{dl})$ and troponin $\mathrm{T}$ $(0.1 \mathrm{ng} / \mathrm{ml})$ were normal. His vitamin $\mathrm{D}$ level was $8.1 \mathrm{ng} / \mathrm{mL}$ (normal values for infants- $20-70 \mathrm{ng} / \mathrm{ml}$ ) which was treated with a cumulative dose of 600,000 IU of vitamin D over 10 days. Echocardiography showed severe ventricular dysfunction with an ejection fraction of $8-10 \%$. Aspirin $3 \mathrm{mg} / \mathrm{kg} /$ day was started. As the heart rate was fluctuating between $100-190 / \mathrm{min}$, the dose of amiodarone was increased to $10 \mu \mathrm{g} / \mathrm{kg} / \mathrm{min}$. On day 2 of admission the infant went on to have SVT for which two doses of adenosine $(0.1 \mathrm{mg}$ per $\mathrm{kg}$ followed by $0.2 \mathrm{mg}$ per $\mathrm{kg}$ ) were given but the rhythm did not come back to normal. Synchronized cardioversion was done with energy of 1 joule $/ \mathrm{kg}$. Immediately normal rhythm was achieved (Figure 2).

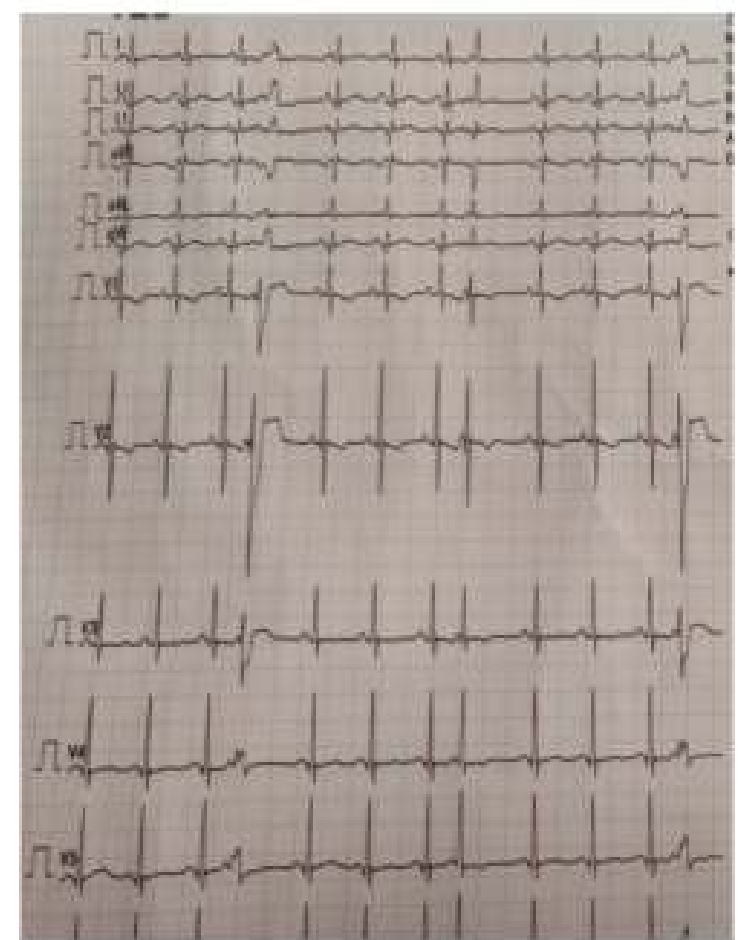

Figure 2: post cardioversion ECG showing normal rhythm with one atrial premature contraction

However, amiodarone was continued considering the resistant nature of the arrhythmia. Infant still intermittently had tachyarrhythmia up to $220 / \mathrm{min}$ with SVT. On day 5, child was relatively stable, started to accept feeds and did not show fluctuation in heart rate; hence oral amiodarone $10 \mathrm{mg}$ per $\mathrm{kg}$ per day was started and slowly the amiodarone infusion was tapered off. However, his milrinone requirement was persistent as he had relatively cold peripheries with normal blood pressure $(74 / 50 \mathrm{~mm}$ $\mathrm{Hg}$ ) and CRT was 3 seconds; hence it was decided to give him infusion of levosimendan in a dose of $0.1 \mu \mathrm{g} / \mathrm{kg} / \mathrm{min}$, as it has a longer duration of action (up to 7 days) for 24 hours and milrinone was tapered and stopped.

On admission, oxygen was started by nasal prongs at 2 litres/min. On day 7 of admission, we were able to taper off oxygen. His repeat echocardiography showed normal ejection fraction (45-50\%). On day 12, child was discharged with a stable heart rate and normal rhythm. He was discharged on amiodarone $5 \mathrm{mg} / \mathrm{kg} / \mathrm{day}$, digoxin $5 \mu \mathrm{g} / \mathrm{kg} / \mathrm{min}$ and furosemide $1 \mathrm{mg} / \mathrm{kg} /$ day. On follow up on day 15 of discharge, $2 \mathrm{D}$ echo cardiography was repeated and was normal. We stopped digoxin and furosemide. The child was growing well with normal development at 3 months after discharge with normal heart rate and rhythm and amiodarone was stopped. This was a rare case of resistant atrial flutter causing cardiomyopathy which was successfully managed with repeated cardioversion, amiodarone and digoxin.

\section{Discussion}

$\mathrm{AF}$ is generally well tolerated by infants ${ }^{1}$. ECG can diagnose AF which generally demonstrates a $2: 1$ to $4: 1$ atrioventricular conduction. Though structural heart disease is uncommon in AF, getting an echocardiogram done is important to assess ventricular function especially in acutely ill infants. As, in our case, ventricular function was grossly affected on admission, ejection fraction being 8$10 \%$, AF must have been prolonged. Investigations done for myocarditis were normal. A study by Naheed ZJ, et $a l^{6}$ showed that development of symptoms do not correlate with atrial or ventricular rates or conduction ratio but is rather associated with the duration of the arrhythmia. There are reports of spontaneous conversion to normal rhythm ${ }^{1}$. Some studies report the success rate of $90 \%$ of cardioversion in AF returning to normal sinus rhythm ${ }^{7}$. In our patient, because of recurrent episodes, a combination of cardioversion, digoxin, propranolol and amiodarone were used. Digoxin has been recommended in the treatment of neonatal AF. However, there is the raised risk of ventricular tachycardia accompanying cardioversion after digitalization $^{8}$. In our case, patient was not digitalized and was directly started on maintenance therapy before referring to us. AF in infants can be resistant especially to first line therapies like betablockers and digitalis ${ }^{9}$. Therefore, second line therapies like cardioversion, amiodarone or flecainide might be needed ${ }^{9}$. Infants with AF carry an excellent prognosis once they have reverted to sinusoidal rhythm and long-term antiarrhythmic drugs may not be needed. In our case it was continued for 3 months, and then stopped.

In summary, AF in young infants can sometimes be symptomatic $^{1}$. They are diagnosed with ECG showing typical pattern of saw tooth appearance; 2 
D echocardiography should be done in all cases to rule out structural malformation and to assess ventricular function. If patient shows symptoms of decompensation, cardioversion is the treatment of choice with $0.5-1$ joules $/ \mathrm{kg}$. In case of recurrences, second line therapy like amiodarone or flecainide can be considered.

\section{References}

1. Texter KM, Kertesz NJ, Friedman RA, Fenrich Jr AL. Atrial flutter in infants. Journal of the American College of Cardiology 2006; 48: 1040-6.

https://doi.org/10.1016/j.jacc.2006.04.091

PMid: 16949499

2. Badrawi N, Hegazy RA, Tokovic E, Lotfy W, Mahmoud F, Aly H. Arrhythmia in the neonatal intensive care unit. Pediatric Cardiology 2009; 30: 325-30. https://doi.org/10.1007/s00246-008-93554

PMid: 19184182

3. Southall DP, Johnson AM, Shinebourne EA, Johnston PG, Vulliamy DG. Frequency and outcome of disorders of cardiac rhythm and conduction in a population of newborn infants. Pediatrics 1981; 68: 58-66.

4. Moller JH, Davachi F, Anderson RS. Atrial flutter in infancy. Journal of Pediatrics 1999; 75: 643-51. https://doi.org/10.24953/turkjped.2018.03. 011

PMid: 30511544
5. Luewan S, Sittiwangkul R, Srisupundit K, Tongsong $T$. Perinatal treatment of refractory atrial flutter with hydrops fetalis: a case report. Journal of the Medical Association of Thailand 2011; 9: 878-81.

6. Naheed ZJ, Strasburger JF, Deal BJ, Benson W, Gidding SS. Fetal tachycardia: mechanisms and predictors of hydrops fetalis. Journal of the American College of Cardiology 1996; 27:1736-40. https://doi.org/10.1016/07351097(96)0005 4-X

7. Lisowski LA, Verheijen PM, Benatar AA, et al. Atrial flutter in the perinatal age group: Diagnosis, management and outcome. Journal of the American College of Cardiology 2000; 35: 771-7.

https://doi.org/10.1016/S07351097(99)00 589-6

8. Kleiger R, Lown B. Cardioversion and digitalis: II. Clinical studies. Circulation 1966; 33: 878-87.

https://doi.org/10.1161/01.CIR.33.6.878

PMid: 5940516

9. Yilmaz-Semerci S, Bornaun H, Kurnaz D, et al. Neonatal atrial flutter: Three cases and review of the literature. Turkish Journal of Pediatrics 2018; 60(3):306-9. https://doi.org/10.24953/turkjped.2018.03. 011

PMid: 30511544 